\title{
Outcome of Childhood Acute Lymphoblastic Leukaemia after Induction Therapy - Three-Year Experience in a Tertiary Care Hospital in Bangladesh
}

\author{
M. Belayet Hossain ${ }^{1}$, M Selimuzzaman ${ }^{2}$, Nilufar Akter Banu Choudhury ${ }^{3}$, Abdul Wahab ${ }^{4}$, \\ Fazlur Rahman Choudhury ${ }^{4}$, Sajeda Sultana ${ }^{4}$, Hasan Mehedi ${ }^{4}$ \\ Received: July 26, 2016 Accepted: November 5, 2016 \\ doi: http://dx.doi.org/10.3329/jemc.v7i1.30747
}

\begin{abstract}
Background: The incidence of different malignancies is increasing among the world populations. Acute lymphoblastic leukaemia (ALL) is the most common of all the paediatric malignancies. Response to induction therapy is one of the most important predictors of long term outcome of ALL. Objective: To see the immediate outcome of paediatric ALL patients following induction therapy. Materials and Methods: This retrospective study was conducted from January 2013 to December 2015. Total 221 paediatric ALL patients were included in this study. Diagnosis was based on history, examination, blast cells count on peripheral blood film and bone marrow study, CSF study and immunophenotyping of peripheral blood/bone marrow aspirate in patients who were financially capable. Among them, parents of 40 (18\%) patients did not agree to start chemotherapy. According to Modified UK ALL 2003 protocol (Regimen $A \& B) 181$ patients were given induction therapy (vincristine, prednisolone, L-asparaginase, and daunomycin) in high risk patients. Among them 14 patients discontinued, 10 patients died during chemotherapy and rest 157 patients completed induction phase. Bone marrow study was repeated after completion of induction therapy and remission pattern was seen. Results: Out of 157 chemotherapy completed patients, 137 (87\%) went into complete remission $(<5 \%$ blast cells in bone marrow), 14 (9\%) into partial remission (5-25\% blast cells in bone marrow) and 6 (4\%) was not in remission (>25\% blast cells in the bone marrow). Ten (5.5\%) patients died due to bleeding, febrile neutropenia and sepsis during the course of induction therapy. Conclusion: ALL in children is curable with effective chemotherapy. Poverty, ignorance and misconception regarding outcome are responsible for refusal and discontinuation of chemotherapy in third world countries like Bangladesh. Mortality and treatment cost can be reduced with the improvement of the facilities for isolation, barrier nursing and supportive treatment, and by creating awareness.
\end{abstract}

Key words: Acute lymphoblastic leukaemia; Induction therapy; Outcome

\section{J Enam Med Col 2017; 7(1): 25-28}

\section{Introduction}

Acute leukaemia is the most common form of malignancy in children, comprising approximately $30 \%$ of all childhood malignancies. ${ }^{1}$ Of acute leukaemias, acute lymphoblastic leukaemia occurs five times more commonly than does acute myeloid leukaemia. ${ }^{2}$ A

1. Associate Professor, Department of Paediatric Haemato-Oncology, Bangladesh Institute of Child Health, Dhaka Shishu (Children) Hospital, Dhaka

2. Associate Professor, Department of Paediatric Haemato-Oncology, Bangladesh Institute of Child Health, Dhaka Shishu (Children) Hospital, Dhaka

3. Registrar, Department of Paediatric Haemato-Oncology, Bangladesh Institute of Child Health, Dhaka Shishu (Children) Hospital, Dhaka

4. Medical Officer, Department of Paediatric Haemato-Oncology, Bangladesh Institute of Child Health, Dhaka Shishu (Children) Hospital, Dhaka

Correspondence M. Belayet Hossain, Email: belayethossain9@gmail.com 
sharp peak of ALL incidence is observed at 2-5 years of age. ${ }^{2}$ There has been a gradual increase in the incidence of ALL in the past 25 years. $^{3}$ Hopefully survival rates for ALL have improved dramatically since 1980s with a current five-year overall survival rates greater than $85 \% .^{4-6}$ This improvement is due to treatment of a large number of children in sequential standardised research protocols. Treatment of children with ALL is divided into several stages: remission induction, consolidation or intensification, and maintenance (continuation) therapy with CNS prophylaxis therapy generally provided in each stage.

The goal of induction therapy is to bring the disease into remission (patient's blood counts return to normal and bone marrow shows no signs of disease). Usually three-drug induction therapy using vincristine, prednisolone/dexamethasone, plus Lasparaginase in conjunction with intrathecal therapy (IT) results in complete remission rates of greater than $95 \% .^{7-9}$ Patients with increased risk require anthracycline (e.g., daunomycin). Protocols using this 4-drug combination with intensive consolidation and maintenance therapy uniformly demonstrate improved overall remission duration, even for high risk patients. ${ }^{10-11}$

The initial response to remission induction therapy is one of the most important prognostic factors in acute lymphoblastic leukaemia (ALL). Patients who respond slowly have a high risk of relapse, while those who fail to attain a complete remission within 4-6 weeks of treatment have dismal prognosis. ${ }^{12}$ This study analyses the results of three to four-drug induction chemotherapy in the department of Paediatric Haemato-Oncology of Dhaka Shishu (Children) Hospital, Dhaka, Bangladesh.

\section{Materials and Methods}

This retrospective study was conducted in the department of Paediatric Haemato-Oncology of Dhaka Shishu (Children) Hospital, Dhaka, Bangladesh from January 2013 to December 2015.

Total 221 newly diagnosed paediatric patients of ALL during this period were included in this study. Patients who had relapsed ALL, infantile leukaemia, and who were given chemotherapy elsewhere were excluded from the study. Patients remained admitted in the oncology ward for the whole duration of induction therapy.
After history and clinical examination, $\mathrm{CBC}$, peripheral blood film and bone marrow biopsy/aspirate were seen for detection of blasts cells. Immunophenotyping by flowcytometry was done on peripheral blood sample or bone marrow aspirate for patients who were financially capable. Serum electrolytes, liver and renal function tests, tumour lysis profile, blood culture, CSF and chest radiography were also done. Patients were stabilised haemodynamically by packed cells transfusion if haemoglobin level was less than $8 \mathrm{gm} / \mathrm{dL}$, platelets transfusion if platelet count was $<20,000 / \mathrm{mm}^{3}$. Tumour lysis prophylaxis was started in the form of adequate hydration, allopurinol, phosphate binder and treatment of hyperkalemia and hypocalcaemia where needed. For febrile neutropenia (ANC $<1.0 \times 109 / \mathrm{L}$ plus fever $\geqslant 38^{\circ} \mathrm{C}\left(100.4^{\circ} \mathrm{F}\right)$ for $>4$ hours or single spike of $\geqslant 38.5^{\circ} \mathrm{C}\left(101.3^{\circ} \mathrm{F}\right)$ proper antibiotics were started.

Parents of 40 patients out of 221 did not agree to start chemotherapy. In the rest 181 patients four-drug induction therapy was started according to Modified UKALL 2003 Protocol (Regimen A\&B) with vincristine, dexamethasone/ prednisolone, L-asparaginase, and daunomycin. Intrathecal methotrexate, cytarabine and hydrocortisone were given on day 1 and day 28. Among them 14 patients discontinued chemotherapy and 10 patients died during chemotherapy. The rest 157 patients completed induction phase. Bone marrow study was repeated at the end of induction therapy to see the remission. Remission pattern was noted - whether complete remission $(<5 \%$ blasts cells in the bone marrow), partial remission (5-25\% blast cells) or no remission ( $>25 \%$ blast cells).

\section{Results}

Among the 221 patients, $146(66 \%)$ were males and 75 (34\%) were females. Mean age of the subjects was 5.5 years (2-14 years).

Pallor was noted in 201 (91\%), fever in 186 (84\%), bleeding manifestation in 99 (45\%), hepatosplenomegaly in 177 (80\%), lymphadenopathy in 139 (63\%) and mediastinal mass in $7(3.1 \%)$ patients (Fig 1$)$.

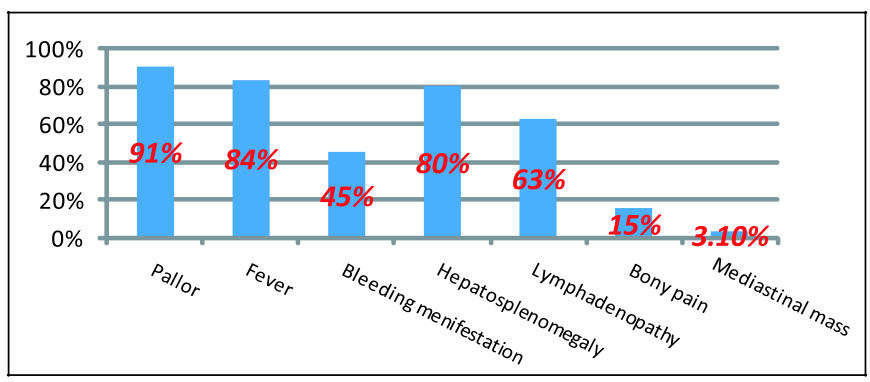

Fig 1. Clinical manifestations of study subjects $(n=221)$ 
Total leucocyte count (TLC) was $<50,000 / \mathrm{mm}^{3}$ in 152 $(69 \%)$ and $>50,000 / \mathrm{mm}^{3}$ in $69(31 \%)$ patients. Blast cells were detected in 201 (91\%) patients in peripheral blood film (PBF) with range of 2-96\% and not detected in $20(9 \%)$ patients. All the 221(100\%) patients showed blast cells in bone marrow biopsy/aspirate. CSF from all the patients showed no blast cell (Fig 2).

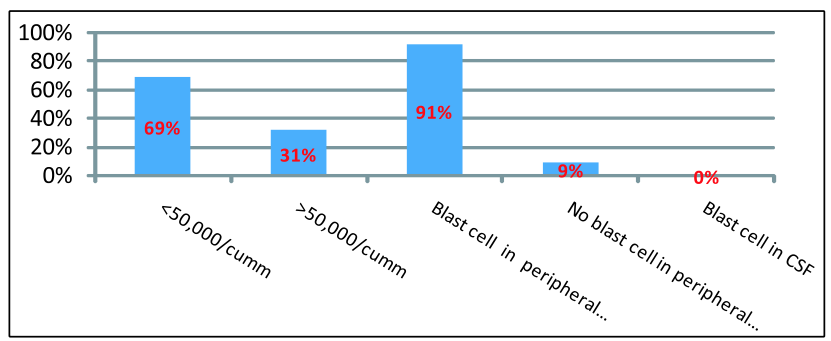

Fig 2. Laboratory profile of study subjects $(n=221)$

Parents of 40 (18\%) patients refused to start chemotherapy and parents of 14 (6\%) patients could not continue chemotherapy due to financial constraint. Ten $(5.5 \%)$ patients died due to bleeding, febrile neutropenia and sepsis during the course of induction therapy. The duration of induction phase was prolonged in many patients due to occurrence of agranulocytosis, thrombocytopenia, altered liver functions and due to lack of proper isolation as well as barrier nursing facilities.

Bone marrow study was done in remaining 157 patients after induction therapy. Out of 157 induction completed patients, $137(87 \%)$ went into complete remission $(<5 \%$ blast cells in bone marrow), 14 (9\%) into partial remission (5-25\% blast cells in bone marrow) and 6 (4\%) was not in remission ( $>25 \%$ blast cells in the bone marrow) (Fig 3).

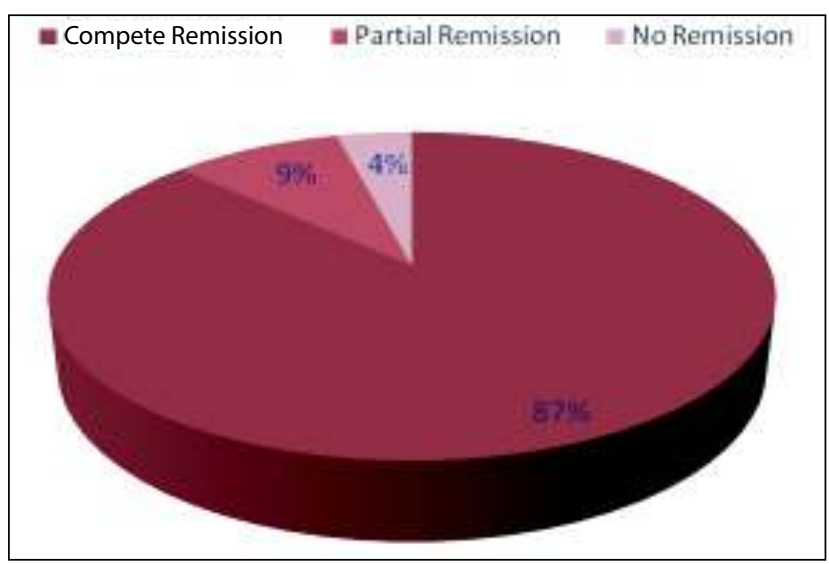

Fig 3. Bone marrow remission pattern after induction therapy $(n=157)$

\section{Discussion}

It is widely accepted that the combination of dexamethasone/prednisolone, vincristine and Lasparaginase is essential for remission induction. The addition of daunomycin appears to be advantageous in high risk patients. 7,8

A study by Laningham et $\mathrm{al}^{13}$ showed that only $3 \%$ of patients had detectable CNS involvement at the time of diagnosis ( $\geqslant 5 \mathrm{WBC} / \mu \mathrm{L}$ with lymphoblasts present). In our study, no patient presented with CNS leukaemia at diagnosis, so we administered only prophylactic intrathecal chemotherapy to all patients.

In comparison to developed countries, the incidence of drop-out of patients was more in our study. This might be due to poverty and misconception regarding outcome amongst our population.

Supportive care of the paediatric cancer patient has played an increasingly important role in the management of these critically ill patients. As intensity of primary treatment has escalated, the side effects such as myelosuppression and infection have also increased. ${ }^{14}$

MRC UK ALL X study showed that 2-3\% of all patients died during induction or in remission, most frequently due to leucostasis, bleeding or opportunistic infections such as Gram-negative septicaemia and pneumocystis carinii pneumonia. ${ }^{15}$ In our study higher incidence of deaths $(5.5 \%)$ during induction was observed as compared to $2-3 \%$ in the above study. It is mostly due to infection as there was lack of facilities for proper isolation and barrier nursing in our country.

According to a study by Silverman et $\mathrm{al}^{16}$, failure of induction therapy is a relatively rare event occurring in fewer than $5 \%$ of children with ALL treated with current regimens, but in our study the failure of induction therapy was $4 \%$ which is similar.

Regarding prognosis after induction therapy, a study by Steinherzet $\mathrm{al}^{17}$ explained that there are occasional patients who demonstrate partial remission $(>5 \%$ but $<25 \%$ leukaemic blasts) at the end of a standard induction, but in our study the rate of partial remission was a little higher.

Some studies found different predictors for long term outcome of ALL children. ${ }^{12,13,15}$ These predictors include age, WBC count, CNS involvement, gender, leukaemia morphology immunophenotyping, cytogenetics and rapidity to response. ${ }^{18}$ 
A study by Urban et al ${ }^{19}$ showed that improved supportive care has decreased the mortality rate during induction therapy to approximately $3 \%$ or less. But in spite of adequate supportive care and use of appropriate antibiotics, there is higher incidence of mortality (5.5\%) in our patients. This may be due to (a) delayed referral to tertiary care centre, (b) complications of disease at the time of presentation, (c) poor nutrition status, (d) 4drug induction therapy including daunomycin and (e) higher incidence of nosocomial/community acquired infections due to lack of facilities for isolation and barrier nursing.

In this study we have found that escalated four drug induction therapy causes more myelosuppression and infection during induction therapy, which warrants very strict barrier nursing and isolation. In our study high drop-out during induction therapy has been observed. Availability of drugs at lower cost and supportive social care may improve the condition.

Our study reveals that ALL in children is curable with effective chemotherapy. Poverty, ignorance and misconception regarding outcome are responsible for refusal and discontinuation of chemotherapy in third world countries like Bangladesh. Mortality and morbidity as well as treatment cost can be reduced with the improvement of the facilities for isolation, barrier nursing and supportive treatment and by creating awareness.

\section{References}

1. SEER Cancer Statistics Review 1973-1999. National Cancer Institute, National Institutes of Health, Bethesda, MD, USA. Int J Epidemiol 2000; 29: 197-207.

2. McNally RJ, Rowland D, Roman E, Cartwright RA. Age and sex distribution of hematological malignancies in the U.K. Hematol Oncol 1997; 15: 173-189.

3. Shah A, Coleman MP. Increasing incidence of childhood leukemia: a controversy re-examined. Br J Cancer 2007; 97: 1009-1012.

4. Pui CH, Sandlund JT, Pei D, Campana D, Rivera GK, Ribeiro $\mathrm{RC}$ et al. Improved outcome for children with acute lymphoblastic leukemia: results of total therapy study XIIIB at St Jude Children's Research Hospital. Blood 2004; 104: 2690-2697.

5. Gatta G, Capocaccia R, Stiller C, Kaatsch P, Berrino F, Terenziani $\mathrm{M}$ et al. Childhood cancer survival trends in Europe: a EUROCARE Working Group study. J Clin Oncol 2005; 23: 3742-3748.

6. Siegel R, Ward E, Brawley O, Jemal A. Cancer statistics, 2011: the impact of eliminating socioeconomic and racial disparities on premature cancer deaths. CA Cancer J Clin 2011; 61: 212-217.
7. Margolin JF, Steuber CP, Poplack DG. Acute lymphoblastic leukemia. In: Pizzo PA, Poplack DG (eds). Principles and practice of pediatric oncology. $4^{\text {th }}$ edn. Philadelphia: Lippincott Williams \& Wilkins; 2002: 489-544.

8. Pui CH, Relling MV, Downing JR. Acute lymphoblastic leukemia. N Engl J Med 2004; 350: 1535-1548.

9. Ortega JA, Nesbit ME Jr, Donaldson MH, Hittle RE, Weiner $\mathrm{J}$, Karon M et al. L-asparaginase, vincristine and prednisone for induction of first remission in acute lymphocytic leukemia. Cancer Res 1977; 37: 535-540.

10. Reiter A, Schrappe M, Ludwig WD, Hiddemann W, Sauter S, Henze $G$ et al. Chemotherapy in 998 unselected childhood acute lymphoblastic leukemia patients. Results and conclusions of the multicenter trial ALL-BFM 86. Blood 1994; 84: 3122-3123.

11. Gaynon PS, Bleyer WA, Steinherz PG, Finklestein JZ, Littman PS, Miller DR et al. Modified BFM therapy for children with previously untreated acute lymphoblastic leukemia and unfavorable prognostic features. Report of Children's Cancer Study Group Study CCG-193P. Am J Pediatr Hematol Oncol 1988; 10: 42-50.

12. Schrappe M, Reiter A, Ludwig WD, Harbott J, Zimmermann $\mathrm{M}$, Hiddemann $\mathrm{W}$ et al. Improved outcome of childhood acute lymphoblastic leukemia despite reduced use of anthracyclines and cranial radiotherapy. Results of trial ALLBFM 90. German-Austrian-Swiss ALL-BFM Study Group. Blood 2000; 95: 3310-3322.

13. Laningham FH, Kun LE, Reddick WE, Ogg RJ, Morris EB, Pui CH. Childhood central nervous leukemia: historical perspectives, current therapy, and acute neurological sequelae. Neuroradiology 2007; 49: 873-888.

14. Ritcley AK. The pediatric oncology group: supportive care manual. London: Smithkline Beecham; 1996.

15. Wheeler K, Cleesells JM, Bailey CC, Richards SM. Treatment related deaths during induction and in first remission in ALL MRC UKALL X. Arch Dis Child 1996; 74: 101-107.

16. Silverman LB, Gelber RD, Young ML, Dalton VK, Barr RD, Sallan SE. Induction failure in acute lymphoblastic leukemia in childhood. Cancer 1999; 85: 1395-1404.

17. Steinherz PG, Gaynon PS, Breneman JC, Cherlow JM, Grossman NJ, Kersey JH et al. Cytoreduction and prognosis in acute lymphoblastic leukemia - the importance of early marrow response: report from the Childrens Cancer Group. J Clin Oncol 1996; 14: 389-398.

18. Childhood acute lymphoblastic leukemia. Available at: http://www.texasoncology.com/types-of-cancer/leukemia/ childhood-acute-lymphoblastic-leukemia. Accessed October 2016.

19. Urban C, Benesch M, Lackner H, Schwinger W, Kerbl R, Gadner $\mathrm{H}$. The influence of maximum supportive care on dose compliance and survival. Single-center analysis of childhood acute lymphoblastic leukemia and non-Hodgkin's lymphoma treated within 1984-1993. Klin Padiatr 1997; 209: 235-242. 